\title{
ARTICULAÇÕES DISCURSIVAS EM TORNO DO SIGNIFICANTE NATUREZA DA CIÊNCIA: Currículo, formação, política
}

\author{
Clivio Pimentel Junior $\left.{ }^{*}\right)$ \\ A existência do nativo deficiente é necessária para a próxima mentira, e a próxima, e a próxima.
} (BHABHA, 2013, p. 226)

\section{INTRODUÇÃO}

Por meio de um cotejamento eclético de dispositivos teóricos pós-estruturais e pósfundacionais, o artigo analisa as articulações discursivas que têm hegemonizado a nomeação da identidade dos processos escolares de ciências $^{1}$ como Natureza da Ciência. Trata-se de um significante que tem funcionado como ponto nodal ${ }^{2}$ durante décadas, quiçá séculos, nas pesquisas da área de Ensino de Ciências e, nesse período, tem atuado como dispositivo de projeção identitária - perfis - de alunos, de professores, de atividades de ensino, do currículo, da escola e, de modo amplo, do social. Apoiado na teoria do discurso de Laclau e Mouffe (2015), nos estudos culturais de Bhabha (2013) e Hall (2003), e nas teorizações curriculares de Lopes e Macedo (2011), esse trabalho objetiva reativar discursos sedimentados em torno do referido significante com o objetivo de impedir que se fortaleçam a ponto de ser impossível questioná-los. "Reativar discursos é simultaneamente abalar o que se encontra sedimentado, estabelecido como objetivo, como fundamento, como presença plena, e fazer emergir os antagonismos, o caráter indecidível e contingente das alternativas" (LOPES, 2015a, p. 450). Tal movimento implica numa agência política contra-hegemônica cuja base repousa em fundamentos contingentes ${ }^{3}$, tendo em vista seu caráter discursivo, isto é, baseado não em uma suposta racionalidade tida como fundamental, mas provisória e indecidível. Assim, não se trata de uma simples substituição das significações hegemônicas por contra-hegemônicas, mas de uma atitude desconstrutiva com vistas a fazer

\footnotetext{
${ }^{(*)}$ Doutorando em Educação (PPGE/FACED/UFBA). Professor Substituto no Departamento de Educação II, Faculdade de Educação, Universidade Federal da Bahia. Membro do Grupo de Pesquisa Formação em Exercício de Professores FEP/FACED/UFBA. E-mail: clivio.pimentel@gmail.com

${ }^{1}$ Refiro-me às Ciências Naturais, Biologia, Química e Física uma vez que os trabalhos cujo ponto nodal é a Natureza da Ciência, referem-se, sobretudo, a estudos sobre o ensino dessas disciplinas escolares.

${ }^{2}$ A noção de ponto nodal refere-se aos pontos discursivos e aos significantes privilegiados que, atuando com princípios articuladores, fixam parcialmente o sentido de uma cadeia significante (LACLAU; MOUFFE, 2015).

${ }^{3}$ Numa postura pós-fundacional, admite-se que a política repousa sobre fundamentos que, na ausência de um centro capaz de estancar as disputas pelos sentidos, implicam a aceitação do contingente, tornando-a um ato de fundação sempre incompleta, incapaz de fixar em definitivo a significação (MARCHART, 2014; LOPES, 2015a).
}

Revista Teias v. 18, n. 50, 2017 (Jul./Set.): Conversas sobre formação de professores, práticas e currículos 
emergir a indecidibilidade última dos atos de nomeação do real e, por extensão, dos processos escolares como Natureza da Ciência; atos de nomeação entendidos em sua dimensão política, sempre decorrentes de relações de poder, que, ao passo em que se constituem, deixam a marca de uma exclusão constitutiva (HALL, 2003; LACLAU; MOUFFE, 2015). O que se encontra sedimentado, portanto, é sempre proveniente de uma seleção, e não de uma necessidade indiscutível, tornando essa agência o potente mecanismo de desestabilização daquilo que se apresenta como obrigatório.

Esse trabalho insere-se no movimento de ressignificação da política a partir de aportes lacanianos, derridianos e heideggerianos, fazendo da luta política uma luta em torno do poder de significar (LOPES, 2015b). Tal luta passa pela desconstrução dos fundamentos fixos do social bem como dos axiomas essencialistas, objetivistas e realistas fortemente sedimentados pela modernidade filosófica (MARCHART, 2014). Nessa chave interpretativa, “o propósito utópico fixo de mudança social - a sociedade sem poder, sem classes, a sociedade sem desigualdades, sem conflitos, [...] - é abandonado ou pelo menos substituído por agendas contextuais e localizadas, impossíveis de serem enumeradas" (LOPES, 2015a, p. 448). A incorporação desses registros na educação tem levado à problematização dos seus fins sociais, sobretudo aqueles pautados na ideia de emancipação do sujeito centrado, educação para a formação do cidadão transformador social, educação para inserção em comunidades racionais, etc., todas previamente calculadas e antecipadas em identidades fixas (LOPES; MACEDO, 2011; LOPES, 2015a; LOPES, 2015b; PEREIRA, 2015).

Ao inserir-me na disputa pela significação, tento mostrar o quanto o terreno da política é marcado pelo indecidível (MARCHART, 2014), fazendo desta atividade uma luta conflituosa cuja palavra final é impossível. A intenção, portanto, é não ditar um novo fundamento a partir do qual a significação poderia ser estancada; antes, mediante um gesto desconstrutivo, interessa-me mostrar aquilo que algumas significações demandam e, ao mesmo tempo, rejeitam, fazendo emergir o indecidível constitutivo dos atos políticos que nomeiam identidades e, nesse texto, identidades de processos escolares. Essa luta envolve "tentar apresentar outra forma de compreender para além do que já se encontra estabilizado" (LOPES, 2015a, p. 450) e, especificamente nesse texto, provocar uma compreensão outra da identidade dos processos escolares de ciências para além do que a histórica hegemonia tem sedimentado. Para isso, na seção seguinte, desenvolvo os pressupostos teóricos pós-estruturais da teoria do discurso entre os quais tenho caminhado; na terceira seção, apresento alguns sentidos de Natureza da Ciência nas políticas curriculares produzidas por 
comunidades epistêmicas ${ }^{4}$ de pesquisa em Ensino de Ciências e as demandas em torno das quais é significado; na seção final, discorro sobre o exterior que articula tais demandas em torno do referido significante com vistas a defender o risco e a incerteza constitutiva da experiência curricular formativa, tentando manter a educação científica aberta às subjetivações subversivas e imprevisíveis. Isso faz da educação científica um fenômeno complexo e mais amplo do que o treinamento e inserção numa ordem cultural já dada, e faz da política o horizonte inalcançável no qual as negociações identitárias são incessantes, tornando a harmonia final uma imagem utópica acessível apenas na tela da fantasia.

\section{PÓS-ESTUTURALISMO E TEORIA DO DISCURSO}

Foi então o momento em que a linguagem invadiu o campo problemático universal; foi então o momento em que, na ausência de centro ou de origem, tudo se torna discurso - com a condição de nos entendermos sobre esta palavra -, isto é, sistema no qual o significado central, originário ou transcendental nunca está absolutamente presente fora de um sistema de diferenças. A ausência de significado transcendental ${ }^{5}$ amplia indefinidamente o campo e o jogo das significações. (DERRIDA, 2011, p. 409-410)

Inspirado na indeterminação radical expressa nas palavras derridianas, trago à discussão uma passagem que, a meu ver, é uma das mais importantes contribuições da teoria do discurso: “o social é articulação, na medida em que a 'sociedade' é impossível” (LACLAU; MOUFFE, 2015, p. 188). Concordando com Marchart (2014), compreendo que é justamente a partir dessa premissa da teoria do discurso que podemos entender a inevitabilidade da atividade política, sua irredutibilidade $^{6}$, haja vista o caráter incompleto de toda totalidade que se quer plenamente suturada e autodefinida. A invasão da linguagem foi um dos tantos eventos históricos partícipes no forjar de uma ambiência propícia à emergência da noção de impossibilidade da sociedade, ampliando

\footnotetext{
${ }^{4}$ Utilizo o conceito de comunidades epistêmicas tal como formulado por Dias e López (2006), remetendo a uma instância sociológica formada por especialistas reconhecidos e com autoridade legitimada em termos de conhecimento politicamente relevantes associado àquele domínio ou área, que compartilham uma dada normatividade e princípios políticos, epistêmicos, ideológicos e de validação de conhecimento. Nesse trabalho, sua incorporação como recurso heurístico marca a distinção entre jogos de linguagem jogados por distintos sujeitos políticos provisoriamente articulados na disputa pela significação, nesse caso, da educação em ciências.

5 “....] daquilo que propus chamar de significado transcendental, o qual, em si mesmo, em sua essência, não remeteria a nenhum significante, excederia à cadeia dos signos e não mais funcionaria, ele próprio, em um certo momento, como significante" (DERRIDA, 2001, p. 26). O conceito de significado transcendental é marcado pela ideia de um significante agindo de fora do jogo da significação, marcado por uma imobilidade, livre da instabilidade constitutiva da discursividade.

${ }^{6}$ Com isso, subscrevo as conclusões de Lopes (2015b) no rechaço à ideia de que as perspectivas pós-estruturais são marcadas por uma despolitização da teoria curricular.
}

Revista Teias v. 18, n. 50, 2017 (Jul./Set.): Conversas sobre formação de professores, práticas e currículos 
indefinidamente a possibilidade de sua significação. Essa noção permite a criação da sociedade como estrutura aberta $e$ indefinida que resiste às antecipações na forma de prescrições de necessidades $^{7}$ tidas como fundamentais; isto é, fora do tempo, do espaço e do acaso de sua constituição. Soma-se a isto a inspiração lacaniana e sua contribuição com a noção de falta constitutiva, apropriada por Laclau e Mouffe (2015) como recurso heurístico de impedimento da completude do social; isto é, a falta como aquilo mesmo que cria a não-presença definitiva do social, impedindo o seu fechamento. A discursividade se comporta, portanto, como a tentativa, sempre parcial, de preencher essa falta, instituindo, nesse esforço, a própria atividade política (MARCHART, 2014).

A virada lingüística pode ser entendida como um movimento cuja precipitação teve como característica uma profusão de narrativas articuladas em torno da tessitura de fortes críticas ao pensamento positivista, da abertura às ideias estruturalistas e pós-estruturalistas, e dos ataques pósmodernos à epistemologia clássica fundada no realismo. Nesse registro, a realidade passa a ser compreendida discursivamente, afastando a ideia de discurso como instrumento de reflexão do real, numa comum rejeição a posturas realistas que entendem a linguagem como meio neutro de descrição objetiva e positiva do mundo. Ainda nesse registro, torna-se estruturante a noção de que nada na linguagem pode vir definitivamente à presença, isto é, nada na linguagem pode aparecer em plenitude (PETERS, 2000; DERRIDA, 2011; BIESTA, 2013), desfazendo a possibilidade de manifestação de presenças plenas quaisquer que sejam.

$\mathrm{Na}$ teoria do discurso, esta profusão de narrativas críticas atualiza-se na instituição da política como articulação de demandas. Nessa construção, há equivalências entre demandas frente a um exterior representado como ameaça ao atendimento dessas mesmas demandas (MARCHART, 2014; LACLAU; MOUFFE, 2015). Isto é, os elementos apresentam uma irremediável diferença que, provisoriamente, são suavizadas tendo em vista a comum rejeição a um determinado inimigo (LACLAU, 2013). Particularmente nesse estudo, isso põe em xeque, desde já, a ideia de que os sujeitos epistêmicos envolvidos em torno da defesa do significante Natureza da Ciência são constituídos por uma unanimidade monótona de vozes em uníssono. As diferenças irremediáveis entre os sujeitos são apenas estancadas em nome de uma articulação provisória, visando combater um determinado elemento tido como ameaça comum. Não há, portanto, nenhum atributo próprio

\footnotetext{
${ }^{7}$ Destaco que Laclau e Mouffe rejeitam a ideia de necessidade como telos, como antecipação pautada em sentidos finais; aceitam a ideia de necessidade tendo em vista que ela "só existe como limitação parcial do campo da contingência" (LACLAU; MOUFFE, 2015), onde não é possível nenhuma interioridade nem exterioridade metafísica guiando o turbulento corpo social. A contingência opera, portanto, restringindo a manifestação plena de uma suposta necessidade fundamental.
} 
aos agentes e/ou entre os agentes articulados. É a partir dessa comum rejeição que a articulação discursiva hegemoniza provisoriamente um determinado sentido: sua constituição emerge em meio a aglutinações que nada têm de essencial ou positivo entre os elementos articulados, mas se dá pela eliminação de uma diferença comum à cadeia articulatória. É esse exterior constitutivo que forja a identificação, é ele que permite inferir a equivalência entre os elementos que, provisoriamente, engendram momentos nessa cadeia. A articulação que hegemoniza um determinado sentido expressa, portanto, uma tensão insuperável entre a lógica da equivalência e da diferença na ausência de um fundamento comum entre os equivalentes - estes mantêm as diferenças entre si -, apenas um exterior que forja a identificação provisória (MARCHART, 2014; LOPES, 2015a; LACLAU; MOUFFE, 2015). A provisoriedade e a parcialidade da significação nodal privilegiada na cadeia de equivalência advêm da abertura do social, da sua impossibilidade, "resultante, por sua vez, do constante transbordamento de todo discurso pela infinitude do campo da discursividade" (LACLAU, MOUFFE, 2015, p. 188). É o excedente de sentido que impede a fixação absoluta, a inteligibilidade plena do social, impedindo, assim, uma reconciliação final da sociedade consigo mesma.

Nesse trabalho, o caráter conflituoso e parcial da equivalência pode ser entendido como expressão da multiplicidade de nuances que se estabelecem nos debates que giram em torno da Natureza da Ciência e que, na presença de um inimigo comum, são estrategicamente esmaecidas, fortalecendo a hegemonia. Tendo em vista esse aspecto aglutinante frente a um corte antagônico comum, focalizo as práticas de articulação em torno do significante investigado tencionando mostrar não apenas as demandas articuladas, mas o exterior que articula, isto é, aquilo mesmo que tal cadeia significante expulsa ao projetar demandas curriculares e formativas em nome da qualidade da educação em ciências. A empiria a partir da qual opero na construção do posicionamento teórico aqui defendido faz referência a alguns textos acessados na graduação em licenciatura em ciências biológicas, na pós-graduação em educação e em ensino, filosofia e história das ciências, e na docência no ensino superior; trata-se, portanto, de uma seleção autobiográfica de textos e discursos que formei e pelos quais fui formado ao longo da trajetória (in)formativa. Nessa seleção, priorizei trabalhos de revisão bibliográfica cujos debates giram em torno da projeção de objetivos e demandas para o Ensino das Ciências, elencadas a partir do significante Natureza da Ciência. Ainda como critério, dei destaque aos trabalhos amplamente citados nas revisões e, de 
modo geral, nos trabalhos publicados desta área de pesquisa, utilizando a base de dados do Google Acadêmico para verificação de número de citações dos textos. ${ }^{8}$

\section{A NATUREZA DA CIÊNCIA NAS POLÍTICAS CURRICULARES}

Destaco, de início, que o significante Natureza da Ciência tem uma longa história na tradição das pesquisas na área do Ensino de Ciências. A manutenção do referido significante como ponto nodal nas políticas curriculares de comunidades epistêmicas dessa área de pesquisa datam do início do século XX (LEDERMAN, 2006). Decorre desta observação histórica a constatação de que os debates que giram em torno do referido significante apresentam diferentes nuances filosóficas, pedagógicas, políticas e epistemológicas que não pretendo debater nesse texto; apenas ressalto a continuidade do mesmo como ponto nodal em torno do qual argumentos sobre a qualidade da educação científica têm sido historicamente construídos e sedimentados nas pesquisas da área de Ensino de Ciências. Em virtude de sua perenidade histórica, o significante Natureza da Ciência emerge nas pesquisas atuais marcado por uma sobredeterminação ontológica complexa que mescla discursos da teoria e da pedagogia crítica, da filosofia - de racionalistas a relativistas -, e da história da ciência moderna. Isso significa dizer que tal significante vem se constituindo mediante processos históricos de deslocamentos, condensações e disjunções de sentidos, assumindo múltiplas aparências discursivas, ao longo de sua trajetória nas pesquisas em Ensino de Ciências, tornando-o um significante vazio articulado por demandas as mais diversas, inclusive contraditórias entre si. O hibridismo de discursos faz da prática articulatória uma precipitação complexa de demandas que vão desde a necessidade de professores mais bem formados, até a necessidade de uma sociedade mais cientificamente informada, passando também pela formação crítica dos alunos, pela reformulação das práticas de ensino e dos currículos das disciplinas de ciências, pela reformulação de propostas curriculares de formação de professores, etc. Tal hibridismo de discursos toma a forma de uma reedição de preocupações curriculares instrumentais/técnicas e pragmáticas, mescladas às preocupações críticas de um ensino político pautado na distribuição de conhecimento que permita tomadas de decisões sociais responsáveis, de maneira a garantir um determinado projeto de sociedade (DIAS; LÓPEZ, 2006; LOPES; MACEDO, 2011). Numa abordagem histórica,

\footnotetext{
${ }^{8}$ Dentre os textos, selecionei aqueles que apresentavam índice de 60 a 600 citações na base de dados do Google Acadêmico, com alguns ultrapassando 1000 citações (LEDERMAN, 1992; ABD-EL-KHALICK; BELL; LEDERMAN, 1998). Trata-se de trabalhos considerados paradigmáticos nas pesquisas em Ensino de Ciências, amplamente citados em textos de revisão, artigos de sequências de ensino, de formação de professores, de planejamento pedagógico, etc. Destaco, ainda, que são números subestimados, já que esse sistema não consegue reunir todas as citações ao desconsiderar teses e dissertações acadêmicas.
}

Revista Teias v. 18, n. 50, 2017 (Jul./Set.): Conversas sobre formação de professores, práticas e currículos 
Lederman (2006, p. 5) constata, por exemplo, que um das apostas recentes das pesquisas, iniciadas no final dos anos 1990 e início dos anos 2000, é a de que "estudantes e professores aprendem melhor sobre a natureza da ciência se ela é apresentada de maneira reflexiva e explícita9"; isto é, há articulações de demandas em torno do vínculo entre o trabalho dos que fazem ciência ao trabalho dos que a ensinam, como forma de superar uma suposta falta transparência dos métodos e conhecimentos científicos na escola:

Não existe consenso sobre os conteúdos específicos a serem incluídos nos cursos de ciências, nem mesmo sobre os métodos/estratégias de instrução a serem usadas. No entanto, parece haver um forte acordo sobre, ao menos, um dos objetivos da instrução científica. O desenvolvimento de um "adequado entendimento da natureza da ciência" [...] continua a ser convincentemente advogado como um desejo da instrução científica. Pesquisas relacionadas à natureza da ciência podem ser convenientemente distinguidas em quatro linhas de pesquisas diferentes, mas relacionadas: (a) avaliação da concepção dos estudantes da natureza da ciência; (b) desenvolvimento, uso e avaliação de desenhos curriculares voltados à sofisticação da concepção dos estudantes da natureza da ciência; (c) avaliações da, e tentativas de sofisticar, as concepções dos professores da natureza da ciência; (d) identificação das relações entre a concepção dos professores, as práticas em sala de aula, e as concepções dos alunos. [...] Através da história da pesquisa sobre as concepções de estudantes e professores sobre a natureza da ciência, muito criticismo tem sido colocado sobre os professores, primeiramente, e sobre os alunos, em menor grau, no que diz respeito à posse de concepções inadequadas. [...] Infelizmente ou não, a natureza ou complexidade da concepção de natureza da ciência que se possui pode ser ainda um outro fator, o qual interage com a já conhecida miríade de significantes fatores variáveis numa sala de aula. (LEDERMAN, 1992, p. 331-353)

Importante destacar que, apesar de não haver definições explícitas sobre o que deve ser ensinado, isto é, sobre quais os conteúdos, em sua variedade de tipos, podem afiançar a presença da natureza da ciência, parece não haver espaço, nos trabalhos, para a problematização desse próprio objetivo do ensino. Ou seja, sua condição universalista e perene como objetivo da instrução científica é indiscutível, restringindo o debate apenas àquilo que, como conhecimento-meio, poderia assegurar sua presentificação nos diferentes contextos escolares. Além disso, historicamente, há um deslocamento intenso de foco nas pesquisas da área de Ensino de Ciências que transita desde o estudo das concepções de ciência dos alunos à dos professores, passando pelas propostas curriculares tanto das escolas quanto dos processos formativos dos professores, estabelecendo vínculos fortes entre esses distintos focos de pesquisa, numa tentativa de mapear a gama de variáveis que interfere na transparência da ciência no espaço escolar (LEDERMAN, 1992;

\footnotetext{
9 "Explícito refere-se a abordagens instrucionais que tornem aspectos da natureza da ciência visíveis em sala de aula" (LEDERMAN, 2006, p. 5).
}

Revista Teias v. 18, n. 50, 2017 (Jul./Set.): Conversas sobre formação de professores, práticas e currículos 
ALTERS, 1997; ABD-EL-KHALICK; BELL; LEDERMAN, 1998; HARRES, 1999). A tentativa de mapeamento das variáveis que interferem na transferência da ciência para a escola, isto é, que produzem resistência e deformam a implementação, tem articulado demandas em torno não apenas de reestruturações curriculares das escolas, mas também da formação de professores, visando vinculá-las aos objetivos educacionais pautados na Natureza da Ciência:

Questões sobre a natureza da ciência tem sido uma preocupação constante para os professores de ciências e desenvolvedores de currículo. Tem sido esperado que o ensino de ciências possa ter um impacto benéfico na qualidade da cultura e na vida publica em virtude dos alunos saberem alguns assuntos da ciência. [...] Há uma longa tradição de estudos teóricos preocupados em estabelecer os benefícios culturais, educacionais e científicos do ensino acerca da natureza da ciência. [...] É irrealista esperar que estudantes ou professores tornem-se competentes historiadores, sociólogos ou filósofos da ciência. Nós devemos ter objetivos limitados ao introduzir questões epistemológicas de natureza da ciências nas aulas: um entendimento mais completo da ciência, não um entendimento total ou muito complexo. (MATTHEWS, 1998)

Tendo sido constatado que estudantes, mesmo após o ensino, ainda apresentam concepções inadequadas, considerou-se plausível atribuir a não modificação desta situação à ineficiência dos currículos de ciências. Porém, o redirecionamento desta área de investigação não ajudou muito a esclarecer a questão. Algumas pesquisas mostram influência do tipo de currículo implementado nas CNC [Concepções sobre a Natureza da Ciência] dos estudantes e outras não evidenciam ganhos significativos em CNC. [...] Na busca da construção de um conhecimento escolar adequado às necessidades educativas de hoje, consideramos imprescindível levar em consideração as concepções científicas e pedagógicas dos professores uma vez que estas constituem uma autêntica epistemologia sobre o conhecimento escolar que influi em suas intervenções práticas. É necessário caracterizá-las, conhecê-las melhor, identificar os seus padrões de evolução para que os processos formativos permitam o seu desenvolvimento crítico e autônomo. [...] Esta correlação entre as CNC e as CD [Concepções Didáticas], representa um resultado atual importante pois, quando da ampla revisão desta área de investigação realizada por Ledermann e publicada em 1992, até aquele momento, a influência das CNC dos professores na sua prática docente estava ainda sem ser adequadamente mostrada. Porém, trabalhos recentes mostram que esta influência têm sido identificada. [...] Os resultados das pesquisas sobre $\mathrm{CNC}$ indicam que os processos formativos em geral não têm propiciado uma reflexão crítica sobre as concepções epistemológicas e as suas implicações didáticas. Há um certo fracasso da formação inicial em promover melhorias na compreensão da CNC e das CD decorrentes. [...] Da mesma forma, os currículos formativos deveriam ser coerentes com CNC mais adequadas e superar as estruturas curriculares comuns, segundo a qual as disciplinas seguem uma ordem sucessiva de momentos de saberes disciplinares, modelo majoritário na formação de professores do Ensino Médio e das séries finais do Ensino Fundamental, e de

Revista Teias v. 18, n. 50, 2017 (Jul./Set.): Conversas sobre formação de professores, práticas e currículos 
momentos de saberes pedagógicos, modelo majoritário na formação de professores para as séries iniciais do Ensino Fundamental. (HARRES, 1999, p. 198-208)

Faria sentido pensar que, tendo nós uma formação científica (Biologia, Física, Química, Geologia) e sendo nós professores de ciências, deveríamos ter adquirido - e, portanto, estaríamos em situação de transmitir - uma imagem adequada do que é a construção do conhecimento científico. No entanto, numerosos estudos têm mostrado que tal não acontece e que o ensino transmite, por exemplo, visões empírico-indutivistas da ciência que se distanciam largamente da forma como se constroem e produzem os conhecimentos científicos. [...] O presente artigo pretende evidenciar a importância de (re)conhecer as visões deformadas dos professores sobre o trabalho científico, para a partir daí poderem consciencializar e modificar as suas próprias concepções epistemológicas acerca da natureza da ciência e da construção do conhecimento científico. [...] Estamos conscientes da dificuldade de falar em uma "imagem correta" da construção do conhecimento científico, que parece sugerir a existência de um método científico universal, de um modelo único de mudança científica. [...] Tal levou-nos a organizar o presente estudo em dois tempos articulados: (I) intentar um consenso sobre o que deveria ser evitado. [...] (II) A nossa conjectura assumiu que a referida imagem pode obter-se diretamente a partir da consideração do que têm em comum as diversas perspectivas e teses epistemológicas de autores como Popper (1962), Khun (1971), Bunge (1976), Toulmin (1977), Lakatos (1982), Laudan (1984), Giere (1988). Para isso, procuramos os ditos pontos comuns com o objetivo de extrair algumas proposições básicas em torno da atividade científica. (GIL PÉREZ et al, 2001, p. 125-127)

Existe uma longa tradição de artigos teóricos sobre os benefícios culturais, educacionais e científicos do ensino acerca da natureza da ciência. A compreensão da natureza da ciência tem sido identificada como um dos aspectos essenciais da alfabetização científica, indispensável à avaliação informada, crítica e responsável das políticas e das propostas científicas e tecnológicas. Considera-se que, numa sociedade científica e tecnologicamente avançada, o exercício da cidadania e a democracia só serão possíveis através de uma compreensão do empreendimento científico e das suas interacções com a tecnologia e a sociedade que permita, a qualquer cidadão, reconhecer o que está em jogo numa disputa sócio-científica, alcançar uma perspectiva fundamentada, e participar em discussões, debates e processos decisórios. [...] Perante este quadro, o ensino da natureza da ciência tem vindo a assumir uma posição de destaque na maior parte dos currículos de ciências das últimas décadas. [...] Contudo, apesar destas referências curriculares explícitas, muitos professores ignoram-nas e continuam a veicular concepções pouco adequadas acerca da natureza da ciência nas suas aulas. Mesmo com orientações curriculares rígidas quanto a conteúdos e metodologias, os professores continuam a tomar as decisões com maior impacto na educação dos alunos, constituindo o elemento mais importante na aprendizagem dos mesmos. (REIS; GALVÃO, 2005, p. 133-134)

As articulações discursivas em torno do significante Natureza da Ciência sustentam uma multiplicidade de subjetivações/identificações de sujeitos epistêmicos diversos, de modo que seria

Revista Teias v. 18, n. 50, 2017 (Jul./Set.): Conversas sobre formação de professores, práticas e currículos 
impossível rastrear os múltiplos pertencimentos dos envolvidos na defesa do referido significante, como se houvessem identidades plenamente firmadas fora do jogo político. A partir da teoria do discurso, restrinjo meu foco à tentativa de perceber quais demandas projetam a partir de tais articulações. Dentre o sem número de demandas, algumas são fortemente pactuadas na defesa da qualidade da educação científica, dentre elas: (I) a necessidade da formação do sujeito racional, portador de conhecimentos científicos capazes de operar mudanças sociais; (II) a necessidade de formação do cidadão emancipado capaz de resolver problemas sociocientíficos os mais diversos a partir de um agir sociopolítico ativo; (III) a necessidade de um fazer curricular tido como científico e que ateste a presença das virtudes críticas da natureza da ciência; (IV) a necessidade de formar professores mais afinados com a filosofia e a história da ciência moderna que possam realizar a educação científica de forma crítica e mais fiel ao que se faz na comunidade científica; (V) a necessidade de currículos de formação para o ativismo socioambiental e para a harmonia social democrática; (VI) a necessidade de suprir uma falta social de conhecimentos científicos, condição para uma vivência democrática harmoniosa, etc. A meu ver, tratam-se de articulações de demandas envolvidas na hipertrofia da razão científica, tida como racionalidade obrigatória e fundamental, capaz de guiar os alunos, professores e, de modo amplo, o comportamento social, em direção a uma comunidade de racionais previamente delineada (BIESTA, 2013). Não apenas a educação é antecipada numa calculabilidade racional, como também o social é projetado como uno, como corpo objetivo, como unidade formada por seres capazes de portar enunciados científicos com maior valor de verdade, buscando atingir consensos entre as mentalidades racionais; uma teleologia do ser em um dever ser cuja presença é previamente elaborada como sujeito que "trabalha por um bom fim ético-político, a paz universal” (LYOTARD, 1998, p. XV). A ideia de portar conhecimentos não aparece por acaso: nessas articulações, as demandas atuam na defesa de que o conhecimento crítico é algo dado, selecionado a partir da ampla tradição científica moderna, anterior à escolarização, cabendo aos professores apenas compartilhá-lo de modo correto, isto é, de modo a garantir a presença da ciência tal como ela realmente é - uma espécie de currículo colecionista pautado no tratamento instrumental do conhecimento como objeto, como coisa que empodera (MACEDO, 2012; TRITTINI; LOPES, 2016).

Por fim, trata-se de articulações políticas que têm hegemonizado a significação da identidade dos processos escolares de ciências como Natureza da ciência, construídas a partir de demandas normativas que postulam o dever ser do ensino (GIL PÉREZ, 1983; GIL PÉREZ; MARTÍNEZ TORREGROSA, 1999), do professor (MATTHEWS, 1995), do currículo da escola (ABD-EL-KHALICK; BOUJAOUDE, 1997) e, por extensão, do social, conferindo, nesse processo, 
superioridade epistemológica à racionalidade científica. Na contramão das discussões curriculares recentes, tais articulações parecem apostar numa radicalização normativa do currículo e da formação - o dever ser -, pautada na possibilidade de existir uma base racional, fundada em princípios notadamente epistemológicos, que possa sustentar as decisões sobre quais os saberes e as atividades de ensino podem garantir a formação de uma subjetividade particular, e, por extensão, a qualidade da educação científica. Ao passo que articula inúmeras demandas, tal significante goza de uma perenidade quase absoluta nas políticas curriculares; perenidade que, como tento mostrar a seguir, pode ser entendida não apenas como uma hegemonia de fato inquestionável, mas também como um anacronismo que marca a impossibilidade de sua realização ou, senão impossibilidade, uma possibilidade marcada pela redução metonímica da educação científica a ensino, com forte vinculação entre ensino, comportamento e cidadania (MACEDO, 2012).

\section{CONSIDERAÇÕES FINAIS - SOBRE O EXTERIOR QUE ARTICULA}

A educação sempre envolve um risco. O risco não é que os professores podem falhar porque eles não estão suficientemente qualificados. O risco não é que a educação pode falhar porque não é suficientemente baseada em evidências científicas. O risco não é que os alunos podem falhar porque eles não estão trabalhando duro o suficiente ou está faltando motivação. O risco está lá porque, como Yeats colocou, educação não é sobre preencher um balde vazio, mas acender uma chama. O risco está lá porque educação não é uma interação entre robôs, mas um encontro entre seres humanos. O risco está lá porque os estudantes não devem ser vistos como objetos a serem moldados e disciplinados, mas como sujeitos de ação e responsabilidade. [...] E a razão para isto reside no simples fato de que, se tirarmos o risco da educação, há uma chance de tirarmos a educação por completo (BIESTA, 2016, p. 1)

Debruço-me, agora, sobre aquilo que é comumente banido, uma suposta identidade do fazer curricular tida como ameaça comum, fazendo tais sujeitos políticos se articularem enquanto comunidade em torno do significante Natureza da Ciência. Considero que a articulação de demandas em torno da tentativa de circunscrever uma pedagogia científica que ateste a formação de um cidadão emancipado e portador das virtudes intrinsecamente críticas da ciência cria como inimigo a identidade de um suposto não-cidadão. Esse não-cidadão pode ser caracterizado como aquele que não consegue portar os conhecimentos da natureza da ciência, aquela que não aprende conforme o pré-escrito, que tem em sua experiência educativa desvios da rota delineada pelas projeções construídas como efeito de aplicação de sequências de ensino - já que, supostamente seguindo a sequência, espera-se imprimir determinados efeitos, competências e habilidades nos sujeitos. Acontece que esse não-cidadão, essa alteridade autorizada e recitada nas prescrições curriculares, é discursiva e estrategicamente construído como um indivíduo localizado, um sujeito 
único, lacunar, que supostamente seria um foco de resistência à expansão da racionalidade tida como fundamental, o que torna este discurso difícil de desestabilizar. De modo similar às conclusões de Macedo (2012), é um indivíduo construído pela retórica da falta, isto é, se a projeção curricular postula uma identidade que serve a todo e qualquer sujeito, o inimigo é um sujeito único que não possui o conhecimento que lhe é externo.

A partir de Biesta (2013), podemos constatar que a linguagem educacional que circunscreve e tenta incluir alguns em alguma comunidade já existente, nesse caso, uma comunidade de sujeitos racionais portadores de conhecimentos científicos capazes de operar transformações sociais numa direção dada, é, ambivalentemente, a mesma que cria a exclusão. Nessa linguagem, a educação fica reduzida à socialização e reconhecimento, isto é, à “inserção do indivíduo humano numa ordem preexistente" (BIESTA, 2013, p. 25). Nesse sentido, é possível constatar que o exterior que articula é constituído por aqueles que podem não seguir os caminhos esperados, em outras palavras, aqueles que podem trazer à tona a impossibilidade da educação - a ideia de que a educação pode seguir caminhos imprevistos, sem a possibilidade de cálculo e antecipação na forma de uma presença fixa (BIESTA, 1998; 2013). Essa ambivalência é, portanto, produtiva, pois, nas políticas emanadas em torno do referido significante, ela torna-se a estratégia de recitação do outro enquanto versão autorizada da alteridade (BHABHA, 2013), sempre deficitária, a condição mesma de possibilidade de operações de valor fronteiriço baseadas em oposições e exclusões. O que pontuo aqui é que essa dupla valência mostra não apenas a possibilidade da educação científica se realizar tal e qual sua projeção, formando sujeitos genéricos e competentes racionais; ela mostra também sua impossibilidade de inclusão total numa suposta comunidade já existente. Ela produz a alteridade inantecipável - o impossível da educação - como aberração do sistema que, resistente à inclusão no círculo racional, torna-se a estratégia de recitação de prescrições curriculares, fortalecendo a própria hegemonia do ponto nodal em torno do qual tais demandas, impossíveis de serem alcançadas, são articuladas. A agência desconstrutiva que tento operar mostra que essa alteridade inantecipável pode ser constitutiva da própria educação científica, tornando ineficaz a linguagem da oposição àquilo mesmo que reside no interior dos processos educativos e não fora como uma anormalidade. Ou seja, aquilo que se permite resistir à antecipação calculada em projeções curriculares é, também, constitutivo da educação científica, não uma anomalia que só entra em cena como aquilo que se quer banir. O exterior que articula demandas em torno da significação da educação científica como Natureza da Ciência é, portando, formado pelo próprio risco da educação (BIESTA, 2016), pela própria alteridade que não se pode pré-ver, pré-escrever, que não se deixa definir em projeções de experiências curriculares formativas. Meu interesse nesse gesto desconstrutivo é defender a 
singularidade no emergir imprevisível dos sujeitos no movimento de diferenciação de si; uma maneira de compreender a educação científica "que não se baseie numa verdade particular sobre o sujeito humano e não veja a educação como um processo de 'produção' de um tipo particular de subjetividade, especialmente o sujeito racional autônomo da educação moderna” (BIESTA, 2013, p. 53). Um modo fraco de compreender o currículo e a escolarização como processos menos finalistas e mecânicos, e mais indeterminados e imprevisíveis, marcados pela impossibilidade última de calcular precisamente experiências educativas, mantendo-os abertos às subjetivações por vir, abrindo-os, assim, a modos outros de ser e estar no mundo que não apenas o científico-racional.

Em outro âmbito de prática articulatória, é possível constatar que o exterior constitutivo é formado por uma suposta prática pedagógica tida como não-científica, incapaz de explicitar a Natureza da Ciência em sua forma original e anterior à eventualidade dos processos escolares. Isso remete, por sua vez, aos professores que, incapazes de realizar explicitamente tal prática pedagógica nos cotidianos das escolas, ficam à margem das significações curriculares tidas como científicas. Em consonância com Macedo (2012; 2014) e Lopes (2015a; 2015b), defendo que, nesse caso, as articulações acabam por nomear como inimigo comum aquilo mesmo que pode ser impossível governar/controlar: a produção irregular e incompleta de sentidos no chão da escola, o imponderável que resiste à nomeação, a textualização sempre diferida e tradutória do currículo, o incontrolável. Nos trabalhos de Lederman (1992; 2006), Reis e Galvão (2005) e Gil Pérez (2001), por exemplo, isso aparece na forma de uma sutil manifestação de pesar frente à impossibilidade de controle rígido da miríade de significantes variáveis que interferem na realização transparente da educação científica. O não controle dos processos simbólicos tradutórios que emergem do/no chão da escola, da formação errante e desviacionista dos professores e alunos, e dos aspectos curriculares formativos mais amplos, que contaminam e borram a concepção que se tem de ciência, é o inimigo comum. Numa moldura que denomino ocularcêntrica, característica dos processos educativos modernos baseados na métrica de atributos visíveis (BIESTA, 2013), a ameaça comum à realização explícita da Natureza da Ciência passa a ser notadamente aquilo que macula a transparência da imagem da ciência ao ser ensinada no cotidiano escolar, isto é, a própria enunciação cultural da ciência. De modo geral, tais manifestações de pesar e tais constatações abrem caminhos investigativos para trabalhos que, como discutido acima, passam a defender alguma modéstia no que diz aos objetivos a serem alcançados pela educação científica (MATTHEWS, 1998), iniciando um processo histórico de diferenciação e suavização das demandas articuladas em torno do referido significante no que diz respeito a uma imagem forte da ciência. No entanto, apesar de modesta, os 
objetivos articulados continuam sendo aproximar a escola da comunidade já dada da ciência, vinculando fortemente ensino, comportamento, cidadania e harmonia social.

Ao me encaminhar para o final do texto, faço algumas considerações sobre o que tem significado, em meus estudos, uma agência político-discursiva. É através da interpretação do exterior constitutivo, daquilo mesmo que é posto fora das nomeações, que deixamos ver de modo mais acirrado os antagonismos, fazendo emergir, na ausência de um fundamento e/ou um porto seguro no qual pudéssemos todos nos amparar, a indecidibilidade. É nesse espaço conflituoso, mas nem por isso improdutivo, que nos resta perceber os jogos de linguagem jogados e tomar decisões, mesmo que em terreno indecidível, sem garantias quaisquer que sejam. Tais percepções colocam os jogos político-discursivos numa situação complexa, de modo que minha intenção aqui é não resolver as tensões, apenas reconhecê-las, deixando o conflito que lhe é constitutivo se mostrar e seguir alimentando as inquietações na forma de um abismo aporético insuperável. Nesta atuação, há sempre um risco de trair a agência pós-estrutural e incorrer numa divisão do tipo nós-eles indesejável, numa espécie de fantasia restaurativa das defesas fundamentais que nos separam narcisicamente de tudo/todos (BUTLER, 2015a; MACEDO, 2015), fundando um confortável e metafísico solo próprio. No entanto, a meu ver, tentar matizar construções do tipo nós-eles significa tentar manter distância dos essencialismos, das supostas positividades das diferenças, do pensamento proprietário e das circunscrições etnocêntricas estereotipadas, deixando os irremediáveis antagonismos emergirem entre os jogos de linguagem jogados nas arenas de disputa pela significação dos processos escolares, nesse caso, de ciências. É por não haver essências plenas que não há uma separação objetiva nem anterior aos atos de subjetivação política: não há sujeito, comunidade, ou qualquer outra estrutura sociológica portadora de consciência e plenitude política anterior aos processos de subjetivação emergentes na própria luta pela significação. Defendo, assim, que só há política em ato de subjetivação, isto é, as posições elaboram-se no caminhar da própria política, de modo que é possível afirmar que nada é anterior a este processo, não há solidez identitária (LOPES; MACEDO 2011; BULTER, 2015a). Não há nenhum nós, como um Isso Mesmo, muito menos um eles, como um Aquilo Mesmo, anteriores e ontologicamente plenos e objetivos, refletidos na operação do espelho no qual a diferença se dissipa como força aprisionada em díades de reconhecimento ${ }^{10}$ (BUTLER, 2015b); ao mesmo tempo, defendo que há sempre, em algum nível diferencial, um nós e um eles, tendo em vista que os termos dos debates jogados nos jogos de linguagem na disputa política - que emergem em ato de subjetivação - expressam também

\footnotetext{
${ }^{10}$ Para uma leitura pós-hegeliana da cena diádica do reconhecimento, ver Butler (2015b).
} 
processos de diferenciação cultural ${ }^{11}$. Defendo que a diferença não está em nenhum dos lados como atributo e, ao mesmo tempo, em ambos enquanto força diferencial, o que contesta nossas certezas e desmancha nossa possibilidade de estar do lado da vitória, haja vista que só há mesmidade simbólica - o nós e o eles condenados a manifestações culturalmente estancadas - na fantasia da solidez sociológica (BHABHA, 2013). Concordando com Macedo (2006; 2015), defendo que nessa chave de leitura não há vitória nem derrota final pelo fato de não haver o fim da história, o telos a guiar para uma suposta conciliação final, numa direção homogeneizante, deixando intocada a linguagem do prêmio e da afirmação narcísica de um dos lados, base de agências políticas essencialistas e proprietárias que sonham com a harmonia. A agência político-discursiva que tenho operado na desestabilização de identidades fundacionais de processos escolares, nesse caso, de ciências, atua mais por uma intencionalidade não diretiva do que por uma prescrição de caminhos, não é uma simples substituição de conteúdos numa mesma moldura; sua intenção reside na ampliação de sentidos democráticos de currículo (LOPES, 2015a) de modo que, sendo emoldurada em guia cega marcada pela irrealizabilidade ${ }^{12}$, torna-se vão procurar o solo confortável que possa nos privar de ter que negociar os sentidos do que seja a educação científica. Resta-nos, assim, aceitar a produtiva incerteza da significação e perceber o quão fantasioso é esperar "o sétimo dia de repouso da atividade política" (LOPES, 2015b, p. 57).

\footnotetext{
${ }^{11}$ Quero apenas destacar a conflitividade do político (LACLAU; MOUFFE, 2015), os impasses entre jogos de linguagem jogados na disputa pela significação, imersos na tensão instituído-instituinte. A intenção é defender o valor heurístico de certa diferenciação sociológica e, ao mesmo tempo, aceitar a indeterminação e a complexidade constitutiva de qualquer instância aglutinativa, evitando a petrificação dos sentidos e a dispersão da diferença entre pólos tidos como próprios e essenciais.

${ }^{12}$ Butler (2004) faz referência ao caráter de resistência à realização plena e final da política democrática, tendo em vista a defesa de seu aspecto aberto e contínuo cujo final é desconhecido, um horizonte sem imagem fixa, sem a possibilidade de vir definitivamente à presença.
}

Revista Teias v. 18, n. 50, 2017 (Jul./Set.): Conversas sobre formação de professores, práticas e currículos 


\section{REFERÊNCIAS}

ABD-EL-KHALICK, F.; BOUJAOUDE, S. An Exploratory Study of the Knowledge Base for Science Teaching. Journal Of Research In Science Teaching, v. 34, n. 7, p. 673-699, 1997.

ABD-EL-KHALICK, F.; BELL, R. L.; LEDERMAN, N. G. The nature of science and instructional practice: Making the unnatural natural. Science education, v. 82, n. 4, p. 417-436, 1998.

ALTERS, B. J. Whose nature of science? Journal of Research in Science Teaching, v. 34, n. 1, p. 39-55, 1997.

BHABHA, H. K. O local da cultura. Belo Horizonte: Ed. UFMG, 2013.

BIESTA, G. Say you want a Revolution... Suggestions for the impossible future of Critical Pedagogy. Educational Theory, v. 48, n. 4, p. 499-510, 1998.

BIESTA, G. Para Além da Aprendizagem: educação democrática para um futuro humano. Belo Horizonte: Autêntica, 2013.

BIESTA, G. The Beautiful Risk of Education. London: Routledge, 2016.

BUTLER, J.; LACLAU, E.; ŽIŽEK, S. Contingencia, Hegemonía, Universalidad: diálogos contemporáneos en la izquierda. Buenos Aires: Fondo de Cultura Económica de Argentina, 2004.

BUTLER, J. Problemas de Gênero: feminismo e subversão da identidade. Rio de Janeiro: Civilização Brasileira, 2015a.

BUTLER, J. Relatar a si mesmo: crítica da violência ética. Belo Horizonte: Autêntica, 2015b.

DERRIDA, J. A Escritura e a Diferença. São Paulo: Perspectiva, 2011.

DIAS, R.E.; LÓPEZ, S.B. Conhecimento, interesse e poder na produção de políticas curriculares. Currículo sem Fronteiras, v. 6, n. 2, p. 53-66, jul./dez. 2006.

GIL PÉREZ, D. Tres paradigmas básicos en la enseñanza de la ciencia. Enseñanza de las Ciencias, v 1, n. 1, p. 26-33, 1983.

GIL PÉREZ, D.; MARTÍNEZ TORREGROSA, J. Cómo evaluar si se hace ciencia en el aula? Alambique, v. 20 , p. 172, 1999.

GIL PÉREZ, D. et al. Para uma imagem não deformada do trabalho científico. Ciência \& Educação, v. 7, n. 2, p. 125153, 2001.

HALL, S. Da diáspora: identidades e mediações culturais. Belo Horizonte: EdUFMG, 2003.

HARRES, J. B. S. Uma revisão de pesquisas nas concepções de professores sobre a natureza da ciência e suas implicações para o ensino. Investigações em Ensino de Ciências, v. 4, n. 3, p. 197-211, 1999.

LACLAU, E. A Razão Populista. São Paulo: Três Estrelas, 2013.

LACLAU, E.; MOUFFE, C. Hegemonia e Estratégia Socialista: por uma política democrática radical. São Paulo: Intermeios, 2015.

LEDERMAN, N. G. Students and teachers conceptions of the nature of science: a review of the research. Journal of Research in Science Teaching, v. 29, n. 4, p. 331-359, 1992.

LEDERMAN, N. G. Research on Nature of Science: reflections on the past, anticipations of the future. Asia-Pacific Forum on Science Education, v. 7, n. 1, Jun., 2006.

LOPES, A. C. Por um Currículo sem Fundamentos. Linhas Críticas, v. 21, n. 45, p. 445-466, mai./ago., 2015 a.

LOPES, A. C. ¿Todavía es posible hablar de un currículum político? In: DE ALBA, A.; LOPES, A. C. (orgs.). Diálogos curriculares entre México y Brasil. Cidade do México: IISUE/UNAM, 2015b.

LOPES, A. C.; MACEDO, E. Teorias de Currículo. São Paulo: Cortez, 2011.

LYOTARD, J. O Pós-Moderno. $3^{\text {a }}$ ed. Rio de Janeiro: José Olympio Editora, 1988.

MACEDO, E. Currículo como espaço-tempo de fronteira cultural. Revista Brasileira de Educação, v.11, n. 32, p. 285372, maio/ago., 2006.

Revista Teias v. 18, n. 50, 2017 (Jul./Set.): Conversas sobre formação de professores, práticas e currículos 
MACEDO, E. Currículo e Conhecimento: aproximações entre educação e ensino. Cadernos de Pesquisa, v. 42, n. 147, p. 716-737, set./dez., 2012.

Base Nacional Curricular Comum: novas formas de sociabilidade produzindo sentidos para educação. Revista E-Curriculum, v. 12, n. 3, p. 1530-1555, out./dez., 2014.

Cultura performativa e pesquisa em educação: desafios para a ação política. Cadernos de Pesquisa, v. 45, n. 158, p. 752-774, Dez., 2015. http://dx.doi.org/10.1590/198053143285

MARCHART, O. Apresentação: teoria do discurso, pós-estruturalismo e paradigma da Escola de Essex. In: MENDONÇA, D. de.; RODRIGUES, L. P. (Orgs.). Pós-estruturalismo e Teoria do Discurso: em torno de Ernesto Laclau. 2a ed. Porto Alegre: EDIPUCRS, 2014.

MATTHEWS, M. História, Filosofia e Ensino de Ciências: a tendência atual de reaproximação. Caderno Catarinense de Ensino de Física, v. 12, n. 3, p. 164-214, dez., 1995.

MATTHEWS, M. In Defense of Modest Goals When Teaching about the Nature of Science. Journal of Research in Science Teaching, v. 35, n. 2, p. 161-174, 1998.

PEREIRA, T. V. Refletindo sobre a tensão entre pesquisa e prática: o caso do ensino de ciências. Educação. Santa Maria, v. 40, n. 2, p. 425-438, mai/ago, 2015.

PETERS, M. Pós-estruturalismo e filosofia da diferença. (Trad.). Tomaz Tadeu da Silva. Belo Horizonte: Autêntica, 2000.

REIS, P.; GALVÃO, C. Controvérsias Sócio-Científicas e Prática Pedagógica de Jovens Professores. Investigações em Ensino de Ciências, v. 10, n. 2, p. 131-160, 2005.

TRITTINI, S. A. C.; LOPES, A. C. Discursos cientificistas nas políticas de currículo no Chile (2003-2013): o foco no Programa ECBI - Enseñanza de las Ciências basada em la Indagación. Ciência \& Educação. Bauru, v. 22, n. 2, p. 279-298, 2016. http://dx.doi.org/10.1590/1516-731320160020002

\section{RESUMO}

Partindo de uma agência pós-estrutural e pós-fundacional, este artigo de posicionamento teórico analisa as articulações discursivas construídas em torno do significante Natureza da Ciência nas políticas curriculares produzidas por comunidades epistêmicas e publicadas em trabalhos acadêmicos da área de Ensino de Ciências. No transcurso da argumentação, defende-se que os sentidos de Natureza da Ciência estão articulados na produção de demandas que, implicadas numa sobredeterminação ontológica que mescla teoria crítica, filosofia e história da ciência moderna, projetam perfis de alunos, de docentes e, de modo amplo, do social, tendo como exterior constitutivo aquilo mesmo que pode ser inextirpável da educação: o risco da/na experiência curricular formativa

Palavras-chave: Currículo; Formação; Política

\section{DISCURSIVE ARTICULATIONS AROUND THE SIGNIFIER NATURE OF SCIENCE: CURRICULUM, FORMATION, POLITICS}

\section{ABSTRACT}

Departing from a post-structural and post-foundational agency, this theoretical positioning paper analyze the discursive articulations built around the signifier Nature of Science in the curricular policies produced by epistemic communities and published in academic works of the area of Science Teaching. In the course of the argument, it is argued that the senses of Nature of Science are articulated in the production of demands that, implied in an ontological overdetermination that mixes critical theory, philosophy and history of modern science, project profiles of students, teachers and, broadly, of the social, having as constitutive exterior that same thing that can be ineradicable of the education: the risk of/in the formative curricular experience

Keyword: Curriculum; Formation; Policy

Submetido em Nov/2016

Aceito em Jul/ 2017

Revista Teias v. 18, n. 50, 2017 (Jul./Set.): Conversas sobre formação de professores, práticas e currículos 